\title{
Anterograde Transport of Tumor Necrosis Factor- $\alpha$ in the Intact and Injured Rat Sciatic Nerve
}

\author{
Maria Schäfers, ${ }^{1,2}$ Christian Geis, ${ }^{1}$ Dominik Brors, ${ }^{3}$ Tony L. Yaksh, ${ }^{2}$ and Claudia Sommer ${ }^{1}$ \\ ${ }^{1}$ Department of Neurology, University of Würzburg, 97080 Würzburg, Germany, and ${ }^{2}$ Anesthesiology Research \\ Laboratory and ${ }^{3}$ Department of Otolaryngology and Neuroscience, University of California San Diego, La Jolla, CA 92093
}

Tumor necrosis factor- $\alpha$ (TNF) appears as a key player at both central and peripheral terminals in early degenerative pathology and pain behavior after peripheral nerve injury. Recent studies suggest that TNF may be axonally transported and thereby contribute to these central and peripheral actions. To characterize this transport, we used a double ligation (DL) procedure that distinguishes between anterograde and retrograde flow to visualize the axonal transport of endogenous TNF compared with the neurotrophin nerve growth factor (NGF) and to the neuropeptide calcitonin gene-related peptide (CGRP). In the intact nerve, TNF and CGRP immunoreactivity predominantly accumulated proximal to the DL (anterograde transport), whereas NGF displayed exclusive retrograde transport. At $20 \mathrm{hr}$ after chronic constrictive injury $(\mathrm{CCl})$, the anterograde transport of TNF and CGRP to the nerve injury site was dramatically increased. The results were corroborated by the analysis of axonal transport of exogenously applied ${ }^{125}$ I-TNF and ${ }^{125}$ I-NGF. After intraneural injection, ${ }^{125} \mathrm{I}-\mathrm{TNF}$ accumulated proximally to a $\mathrm{DL}$, suggesting anterograde transport. In the unligated nerve, ${ }^{125}$ I-TNF was specifically transported anterogradely to the innervated muscle but not to skin. After $\mathrm{CCI},{ }^{125} \mathrm{I}-\mathrm{TNF}$ accumulated proximally to the peripheral nerve injury site, and endogenous TNF was exclusively increased in medium-sized and large dorsal root ganglion (DRG) neurons, suggesting that DRG neurons are a major contributing source of increased TNF traffic in the injured sciatic nerve. Our results suggest that anterograde transport of TNF plays a major role in the early neuronal response to peripheral nerve injury at sites distal to the cell body.

Key words: TNF; axonal transport; chronic constrictive injury; NGF; CGRP; dorsal root ganglion
Pharmacological and physiological studies suggest that proinflammatory cytokines such as tumor necrosis factor- $\alpha$ (TNF) are strongly involved in the generation and maintenance of neuropathic pain (Wagner and Myers, 1996a,b; Sommer and Schäfers, 1998; Sommer et al., 1998). In the intact nervous system, TNF is minimally expressed in the peripheral nerve (Sommer and Schäfers, 1998) and spinal cord dorsal and ventral horn (DeLeo et al., 1997). Early after nerve injury, TNF protein and mRNA at the injury site are upregulated endoneurially primarily in nonneuronal cells (Griffin et al., 1993; Bizette et al., 1996; La Fleur et al., 1996; Wagner and Myers, 1996a; Sommer and Schäfers, 1998; Taskinen et al., 2000), and after a brief temporal delay in dorsal root ganglion (DRG) neurons (Murphy et al., 1995) and the spinal cord (DeLeo et al., 1997). Consistent with a recent report of retrograde axon transport of biotinylated TNF (Shubayev and Myers, 2001) and the observation that nonspecific inhibition of axonal transport abolished neuropathic pain in animal models (Yamamoto and Yaksh, 1993; Sotgiu et al., 1998; Cougnon-Aptel et al., 1999; but see Jakobsen and Sidenius, 1983; Miller and Spencer, 1985; Filliatreau et al., 1994; White et al., 1996; Kingery et al., 1998; Colburn and DeLeo, 1999), we hy-

Received Aug. 20, 2001; revised Oct. 24, 2001; accepted Oct. 30, 2001.

This work was supported by Deutsche Forschungsgemeinschaft Grant SFB 353. We thank M. J. Lohse for the generous use of his radioactive facilities, C. Dees, L. Biko, and B. Dekant for expert technical assistance, and K. V. Toyka for helpful suggestions during the preparation of this manuscript.

Parts of this paper were presented at the 30th Annual Meeting of the Society for Neuroscience, New Orleans, LA, 2000.

Correspondence should be addressed to Dr. Maria Schäfers, Anesthesiology Research Laboratory, University of California San Diego, 9500 Gilman Drive, La Jolla, CA 92093. E-mail: mschaefers@ucsd.edu.

Copyright (ㄷ) 2002 Society for Neuroscience $0270-6474 / 02 / 220536-10 \$ 15.00 / 0$ pothesized that TNF generated by focal nerve injury is carried by fast axonal transport to central or peripheral targets and thereby contributes to the development of pain and early pathology after peripheral nerve injury.

In this study, we examined the axonal transport of endogenous and exogenously applied TNF in the intact and chronically constricted rat sciatic nerve. In the intact nerve, we found an exclusive and rapid anterograde transport of TNF to the muscle but not to skin. After chronic constrictive injury (CCI), the anterograde transport of TNF was strongly increased and stopped at the peripheral nerve injury site. Endogenous TNF was expressed in predominantly small DRG neurons in the intact nervous system, whereas after CCI exclusively medium-sized and large DRG neurons upregulated their expression of TNF. It seems likely that DRG sensory neurons are one of the major contributing sources for increased TNF anterograde transport after nerve injury.

\section{MATERIALS AND METHODS}

Animals. Female Sprague Dawley rats $(200-250 \mathrm{gm}$, in total $n=128)$ were obtained from Charles River (Sulzfeld, Germany). The animals were housed on a $14 \mathrm{hr} / 10 \mathrm{hr}$ light/dark cycle with standard rodent chow and water ad libitum. Experimental groups were composed as follows: (1) experiments of endogenous axonal transport of TNF, nerve growth factor (NGF), and calcitonin gene-related peptide (CGRP) $(n=15) ;(2)$ experiments of exogenous axonal transport with ${ }^{125} \mathrm{I}$-TNF $(n=84)$ and ${ }^{125} \mathrm{I}-\mathrm{NGF}(n=11)$; and (3) experiments of double immunofluorescence in the DRG $(n=6)$ and sciatic nerve $(n=12)$. The several experimental paradigms are described in Figure 1.

Surgery. All surgical procedures used herein were performed under deep barbiturate anesthesia using sodium pentobarbital given intraperitoneally at a dose of $50 \mathrm{mg} / \mathrm{kg}$. To visualize anterograde and retrograde transport of endogenous TNF, NGF, and CGRP, we performed a double ligation (DL) procedure that has been used previously to examine the 

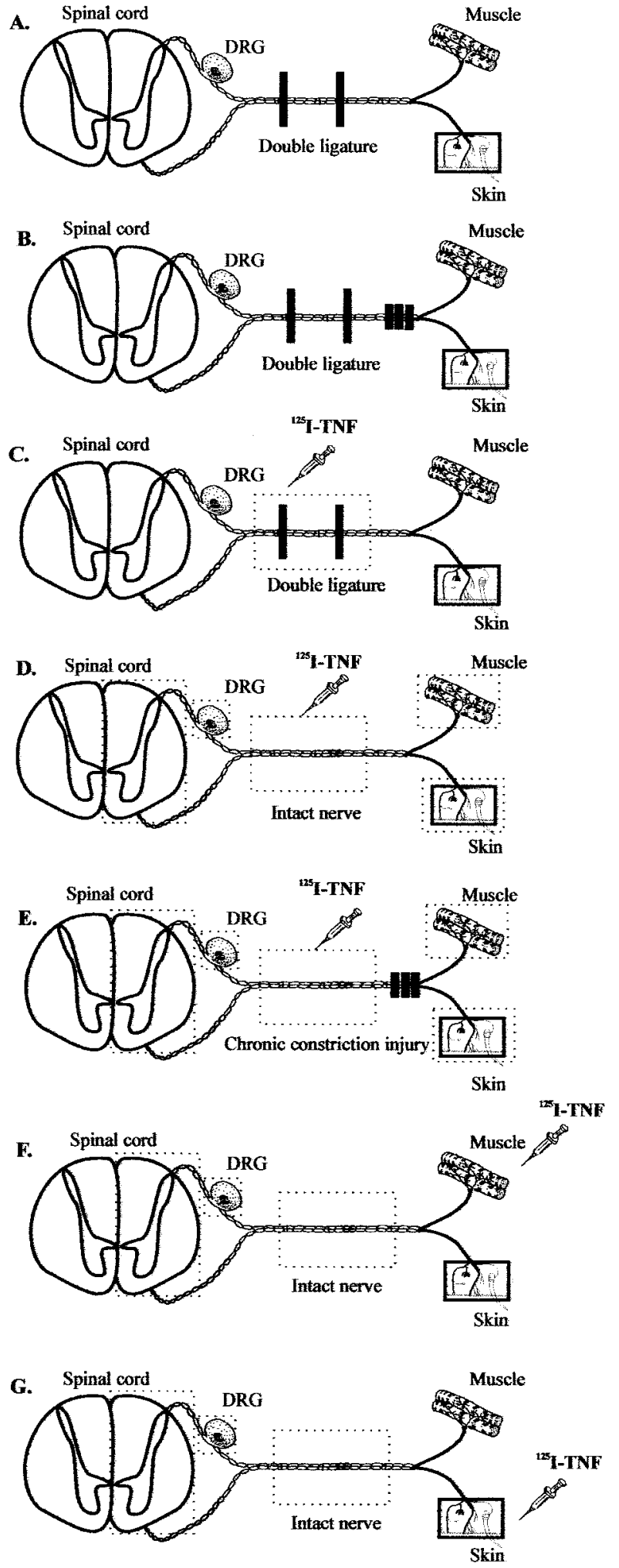

Figure 1. Schematic of the experimental treatments used to determine the axonal transport of endogenous $(A, B)$ and exogenously applied ${ }^{125}$ I-labeled $(C-G)$ TNF. To visualize anterograde and retrograde transport of endogenous TNF, NGF, and CGRP, we performed a DL procedure $(A, B)$. To analyze the axonal transport before and after experimental mononeuropathy, some rats received additionally a bilateral CCI made $1 \mathrm{~d}$ earlier $(B, E)$. For the study of exogenously applied ${ }^{125}$ I-TNF and ${ }^{125} \mathrm{I}-\mathrm{NGF}$, the following paradigms were used: $C$, the radioligands were injected into a double-ligated rat sciatic nerve; $D$, the radioligands were axonal transport of acetylcholinesterase, neurotransmitters, and neurotrophins in the sciatic nerve (Ranish and Ochs, 1972; Ben-Jonathan et al., 1978; Johnson et al., 1987; Zhou and Rush, 1996; Tonra et al., 1998). Ligations consisted of two 4-0 silk ligatures tied tightly around the rat sciatic nerve $8 \mathrm{~mm}$ apart, $1 \mathrm{~cm}$ distal to the tendon of the obturator internus muscle (Fig. $1 A-C$ ). In this model, accumulation of a substance on the proximal (cell body) side provides evidence for anterograde transport from neurons in the spinal cord or DRG, whereas accumulation on the distal (peripheral) side of the double ligature supports retrograde transport. The middle segments provide information about local synthesis (uniform distribution) and accumulation after placement of the ligatures.

To analyze the axonal transport before and after experimental mononeuropathy, some rats received a bilateral CCI as described previously (Sommer and Schäfers, 1998). Briefly, three ligatures (4-0 chromic catgut) were placed around the sciatic nerve with $1 \mathrm{~mm}$ spacing. The ligatures were tightened until they elicited a brief twitch in the respective hindlimb. In these rats, $24 \mathrm{hr}$ later, a DL was placed proximal to the CCI (Fig. 1B).

Axonal transport of endogenous TNF, CGRP, and NGF. After $20 \mathrm{hr}$ or $2 \mathrm{~d}$, the double-ligated nerve was removed for immunostaining. For studies of axonal transport of endogenous TNF, NGF, and CGRP, sciatic nerve tissue was harvested in untreated rats and in rats whose sciatic nerve was constricted $1 \mathrm{~d}$ earlier. Frozen longitudinal cryostat sections at the level of the ligation were cut at $10 \mu \mathrm{m}$, mounted on slides, and incubated overnight at $4^{\circ} \mathrm{C}$ with a polyclonal rabbit anti-rat TNF antibody (Serotec, Oxford, UK), a rabbit anti-rat NGF antibody (Chemicon, Hofheim, Germany), or a rabbit anti-rat CGRP antibody (Peninsula, Heidelberg, Germany). An ABC system (Vector Laboratories, Burlingame, CA) and 3,3' diaminobenzidine tetrahydrochloride were used for detection. Controls included omission of primary antibody (AB) and, in the case of TNF, preabsorption with the antigen.

Axonal transport of exogenous ${ }^{125} I-T N F$ and ${ }^{125} I-N G F$. For studies of axonal transport of exogenously applied TNF, rat ${ }^{125}$ I-TNF (Amersham Biosciences, Freiburg, Germany; specific activity, 400-1200 Ci/mmol) was used to evaluate and quantify the uptake and transport of TNF from within the sciatic nerve, gastrocnemius muscle, or plantar skin. All injections were performed under barbiturate anesthesia. In one group of rats, ${ }^{125}$ I-TNF was injected into the rat sciatic nerve, which was either double-ligated or untreated (Fig. $1 C, D$, respectively). In another group, the sciatic nerve was chronically constricted $1 \mathrm{~d}$ before injection, and ${ }^{125} \mathrm{I}-\mathrm{TNF}$ was injected $2 \mathrm{~mm}$ proximally to the CCI (Fig. $1 E$; in all intraneural injections, $3 \mu \mathrm{Ci}$, in a volume of $5 \mu \mathrm{l}$ ). In another group, ${ }^{125} \mathrm{I}-\mathrm{TNF}$ was injected into gastrocnemius muscle or plantar skin (Fig. $1 F, G$, respectively; for both treatments, $1.5 \mu \mathrm{Ci}$ in a volume of $50 \mu \mathrm{l}$ ). ${ }^{125}$ I-NGF was used as a positive control for exclusive retrograde axonal transport within the sciatic nerve. Six or $20 \mathrm{hr}$ or $3 \mathrm{~d}$ after injection of the radioligands, ipsilateral and contralateral sciatic nerve tissue (Fig. $1 C-$ $G$ ), gastrocnemius muscle (Fig. $1 D, E$ ), plantar skin (Fig. $1 D, E$ ), and L4 and L5 DRG and lumbar spinal cord (Fig. $1 D-G$ ) were dissected. To follow the movement of the radioligands, each sciatic nerve was cut into 10 equal nerve segments (each $2 \mathrm{~mm}$ ). To assess systemic distribution of radioactivity by blood flow, samples of liver, lung, and blood gained by intracardial extraction were dissected from rats of each of the different treatment groups. Radioactivity was measured in all samples directly. Each sample was counted for $5 \mathrm{~min}$ in a gamma counter, and background was subtracted.

Endogenous TNF in the rat sciatic nerve and DRG before and after CCI. Sciatic nerve tissue was harvested from uninjured rats and rats 3 and $12 \mathrm{~d}$ after CCI. Three-millimeter-long sciatic nerve segments distal to the ligatures and corresponding segments from the controls were deepfrozen and processed for histology. Immunofluorescence was performed on $12 \mu \mathrm{m}$ cryosections with a polyclonal rabbit anti-mouse TNF AB (Serotec; 1:500). For double immunofluorescence with TNF, a monoclo-

injected into the intact sciatic nerve; $E$, the radioligands were injected 2 $\mathrm{mm}$ proximally to a CCI of the sciatic nerve made $1 \mathrm{~d}$ earlier; and $F, G$, the radioligands were injected into the gastrocnemius muscle $(F)$ or plantar skin $(G)$. As illustrated by the dotted boxes, the ipsilateral and contralateral sciatic nerve, gastrocnemius muscle, plantar skin, lumbar DRG, and spinal cord were dissected for detection of radioactivity after 6 and $20 \mathrm{hr}$ or $3 \mathrm{~d}$. In the sciatic nerve, $2 \mathrm{~mm}$ segments were separately analyzed. 


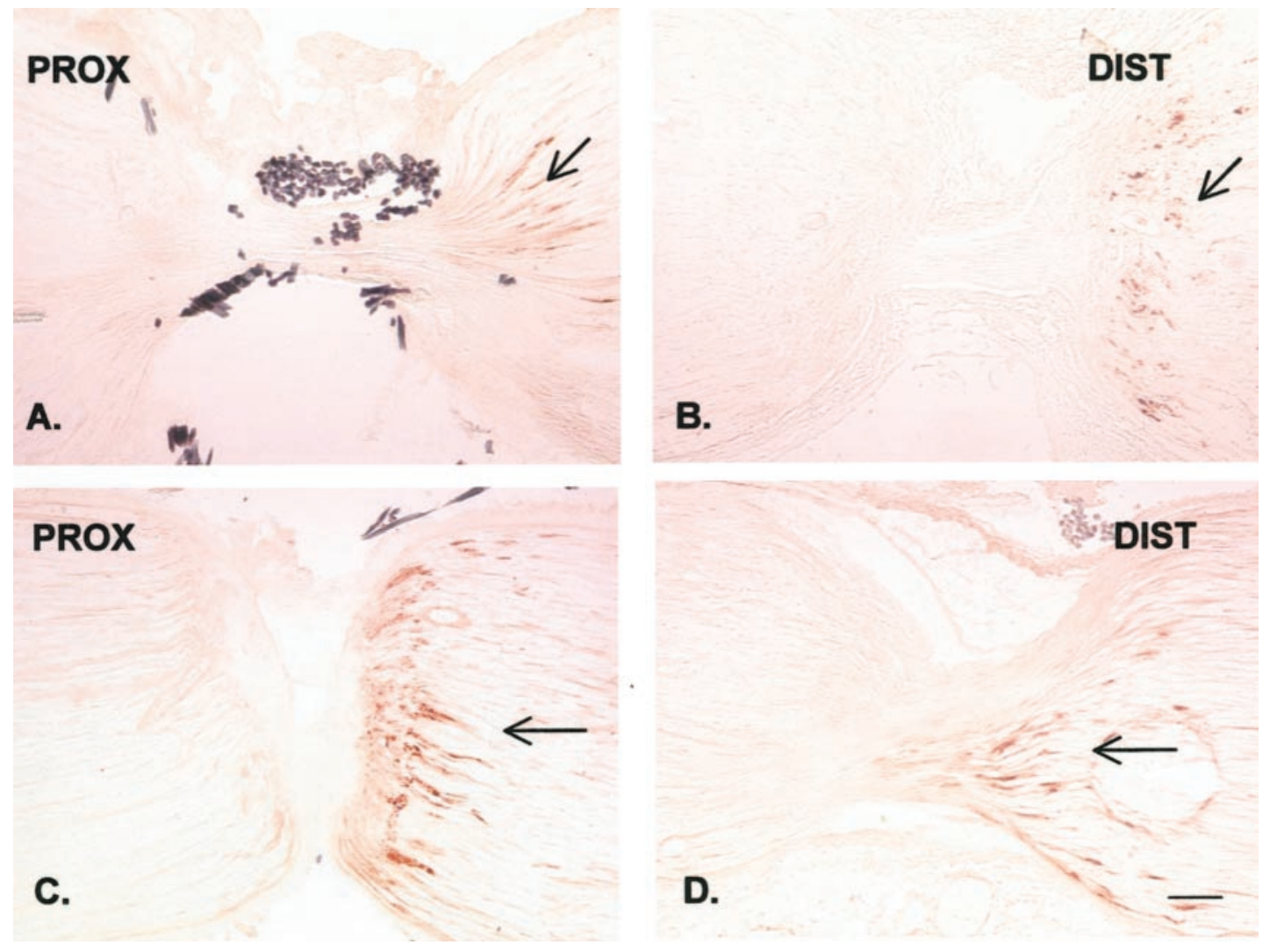

Figure 2. Immunohistochemical staining of endogenous NGF in the rat sciatic nerve proximal (PROX) and distal (DIST) to a DL $20 \mathrm{hr}$ after placement. The proximal (central) side is on the left, and the distal (peripheral) side is on the right. $A, B$, In the double-ligated but otherwise intact nerve, endogenous NGF is accumulating distally to the DL, suggesting exclusive retrograde transport (arrows). $C$, $D$, After chronic constriction injury made $1 \mathrm{~d}$ earlier distally to the DL, the distal accumulation of NGF immunoreactivity is moderately increased (arrows). Scale bar, $100 \mu \mathrm{m}$.

nal mouse anti-rat S100 AB (Chemicon; 1:100) or monoclonal mouse anti-rat ED-1 AB (Serotec; 1:2000) was used as primary AB. A Cy3conjugated secondary AB (Amersham; 1:500) and Cy2-labeled secondary AB (Amersham; 1:500) were used for detection. Lumbar DRGs (L4 and L5) were harvested in uninjured rats and in rats $4 \mathrm{~d}$ after CCI. Every 10th section of serial $10 \mu \mathrm{m}$ cryosections of the L5 ganglion was immunostained for TNF with a Cy3-conjugated secondary AB (Amersham; 1:500) and isolectin IB4 (Sigma, St. Louis, MO; 1:50) with an ExtrAvidin-conjugated secondary AB (Sigma; 1:100). This resulted in an average of 15 stained sections per ganglion.

Morphometry. The immunostained DRG sections were viewed and digitized at a magnification of $100 \times$ with a Zeiss (Oberkochen, Germany) Axiophot 2 microscope using a fully motorized scanning table (Märzhauser) and Image Pro Plus (version 4.0) software (Media Cybernetics Inc., Silver Spring, MD). A density threshold was set to identify the immunoreactive neuronal profiles. The number and cross-sectional area of the immunoreactive profiles were measured and expressed in a histogram.

Statistical analysis. Comparisons of the amount of radioactivity of different tissues and morphometric data were performed by using repeated measures ANOVA followed by a least significant difference post hoc test (Stat View 5.0). References associated with $p<0.05$ were considered statistically significant. All data are given as mean $\pm \mathrm{SE}$.

\section{RESULTS}

\section{Increased anterograde transport of endogenous TNF after chronic constriction injury}

To examine the transport of endogenous TNF in the retrograde or anterograde direction, we used the DL technique. To validate this approach, we examined NGF and CGRP accumulation by immunohistochemistry. At $20 \mathrm{hr}$ after placement of the DL, NGF-IR was visible on the distal side of the distal ligature (Fig.
$2 B$ ) and on the distal side of the proximal ligature (Fig. 2A), confirming its exclusive retrograde axonal transport (Palmatier et al., 1984; Korsching and Thoenen, 1985; Tonra et al., 1998). Because modulation of axonal transport by neuronal injury has been reported for neurotrophins, we next examined the effect of nerve injury on axonal transport. A DL was placed on the rat sciatic nerve proximal to a CCI made $1 \mathrm{~d}$ earlier. After previous nerve injury, the accumulation of NGF-IR distally to both ligatures was moderately increased (Fig. 2C,D). CGRP-IR accumulated proximally and distally to the ligatures $20 \mathrm{hr}$ after placement (Fig. 3A,B) in the double-ligated but otherwise intact nerve, confirming the anterograde and retrograde transport of this neuropeptide (Kruger et al., 1985; IshidaYamamoto et al., 1989; Li et al., 1992; Tonra et al., 1998). After CCI, CGRP-IR proximal to the proximal ligature significantly increased (Fig. 3C), suggesting increased anterograde transport of endogenous CGRP, whereas there was no significant change distally to the ligature (Fig. 3D).

TNF-IR accumulated distally and proximally to both ligatures $20 \mathrm{hr}$ after placement (Fig. 4A,B), suggesting retrograde and anterograde axonal transport in the double-ligated but otherwise intact sciatic nerve. CCI resulted in a significant increase of TNF-IR proximal to the proximal ligation (Fig. $4 C$ ), suggesting upregulated anterograde transport of endogenous TNF after CCI. Distal to the distal ligature or between both ligatures, there was no additional increase of the TNF-IR after CCI, indicating no increase of retrograde transport (Fig. 4D). 

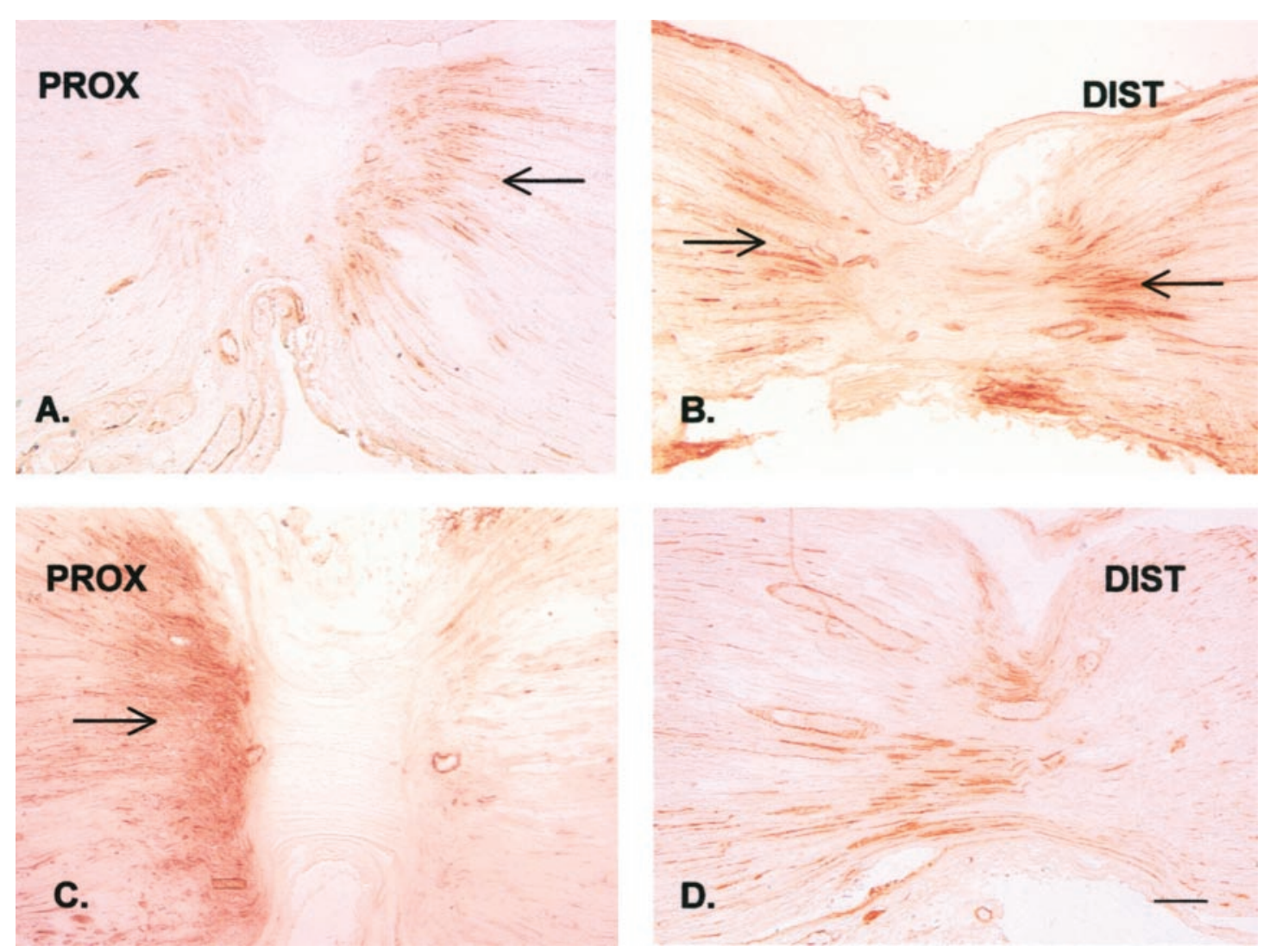

Figure 3. Immunohistochemical staining of endogenous CGRP in the rat sciatic nerve proximal (PROX) and distal (DIST) to a DL 20 hr after placement. As in Figure 2, the proximal (central) side is on the left, and the distal (peripheral) side is on the right. A, B, Endogenous CGRP is accumulating proximally and distally to the DL $20 \mathrm{hr}$ after placement of the ligatures (arrows). $C, D$, After chronic constrictive injury, the accumulation proximally to the proximal ligature is markedly increased $(C$, arrow) without a significant change distally to the ligature $(D)$, suggesting increased anterograde transport. Scale bar, $100 \mu \mathrm{m}$.

\section{Anterograde transport of exogenous ${ }^{125}$ I-TNF in the intact nerve: accumulation of anterogradely transported ${ }^{125}$ I-TNF proximally to the nerve injury}

The immunohistochemical results were corroborated by the analysis of the axonal transport of exogenously applied ${ }^{125} \mathrm{I}-\mathrm{TNF}$ and ${ }^{125} \mathrm{I}-\mathrm{NGF}$. To validate this approach, ${ }^{125} \mathrm{I}-\mathrm{NGF}$ was injected into the double-ligated sciatic nerve (Fig. $1 C$ ), and radioactivity was detected $20 \mathrm{hr}$ later (Fig. 5A). ${ }^{125}$ I-NGF radioactivity was three times greater in the nerve segment distal to the proximal ligature (L1, segment -4 ) than in the segment proximal to the distal ligature (L2, segment $+4 ; p<0.05)$ and five times greater than in the nerve segment proximal to the proximal ligature (L1, segment $-8 ; p<0.05)$. These data demonstrate the predicted retrograde transport of exogenous ${ }^{125} \mathrm{I}-\mathrm{NGF}$. At $20 \mathrm{hr}$ after intraneural injection of ${ }^{125} \mathrm{I}-\mathrm{TNF}$ in a double-ligated nerve (Fig. $5 B$ ), radioactivity significantly accumulated in the nerve segment proximal to the distal ligature (L2, segment +4 ) and was three times greater than in the nerve segments distal to the proximal ligature (L1, segment $-4 ; p<0.05$ ) and distal to the distal ligature (L2, segment +8$)$, suggesting anterograde transport of exogenously applied TNF.

After injection of ${ }^{125} \mathrm{I}-\mathrm{TNF}$ into an intact sciatic nerve (Fig. $6 A$ ), radioactivity accumulated significantly in the sciatic nerve segments distally to the injection (segments $+4,+6$, and +8 vs segments $-4,-6$, and $-8 ; p<0.05)$. Maximal accumulation was achieved after $6 \mathrm{hr}$, suggesting a fast anterograde transport rate of exogenous ${ }^{125} \mathrm{I}-\mathrm{TNF}$. When the sciatic nerve was injured by a chronic constriction injury made $1 \mathrm{~d}$ before intraneural injection of ${ }^{125} \mathrm{I}$-TNF (Fig. $6 \mathrm{~B}$ ), radioactivity accumulated proximally to the CCI nerve segments $20 \mathrm{hr}$ after injection (segments -2 and 0 ) and was not transported across the CCI (segments +6 and +8 ).

\section{No retrograde transport of ${ }^{125} \mathrm{I}-\mathrm{TNF}$ after intramuscular, intradermal, or intraneural injection}

To examine whether skin or muscle afferents were involved in the axonal transport of ${ }^{125} \mathrm{I}-\mathrm{TNF}$, rats were injected intradermally in the foot or into the gastrocnemius muscle with the sciatic nerve intact (Fig. $1 F, G$ ). When ${ }^{125}$ I-NGF was used as a positive control for retrograde transport, radioactivity significantly accumulated in all ipsilateral sciatic nerve segments and DRG $20 \mathrm{hr}$ after intramuscular and intradermal injection (data not shown). After intramuscular or intradermal injection of ${ }^{125} \mathrm{I}-\mathrm{TNF}$, there was no accumulation of radioactivity in the sciatic nerve segments or in the DRG or spinal cord 6 and $20 \mathrm{hr}$ and $3 \mathrm{~d}$ after injection, suggesting no retrograde transport of ${ }^{125}$ I-TNF in skin or muscle afferents to the sciatic nerve (data not shown).

To examine whether endoneurial ${ }^{125} \mathrm{I}-\mathrm{TNF}$ was transported retrogradely to the DRG or spinal cord, ${ }^{125} \mathrm{I}-\mathrm{TNF}$ was injected into the intact rat sciatic nerve. When ${ }^{125} \mathrm{I}-\mathrm{NGF}$ was used as a positive control for retrograde transport, radioactivity significantly accumulated in the ipsilateral DRG. This accumulation was blocked by DL placed on the nerve immediately before intraneural injection (Fig. $7 A ; p<0.05$ ipsilateral DRG in the intact nerve vs ipsilateral DRG with DL). After intraneural 

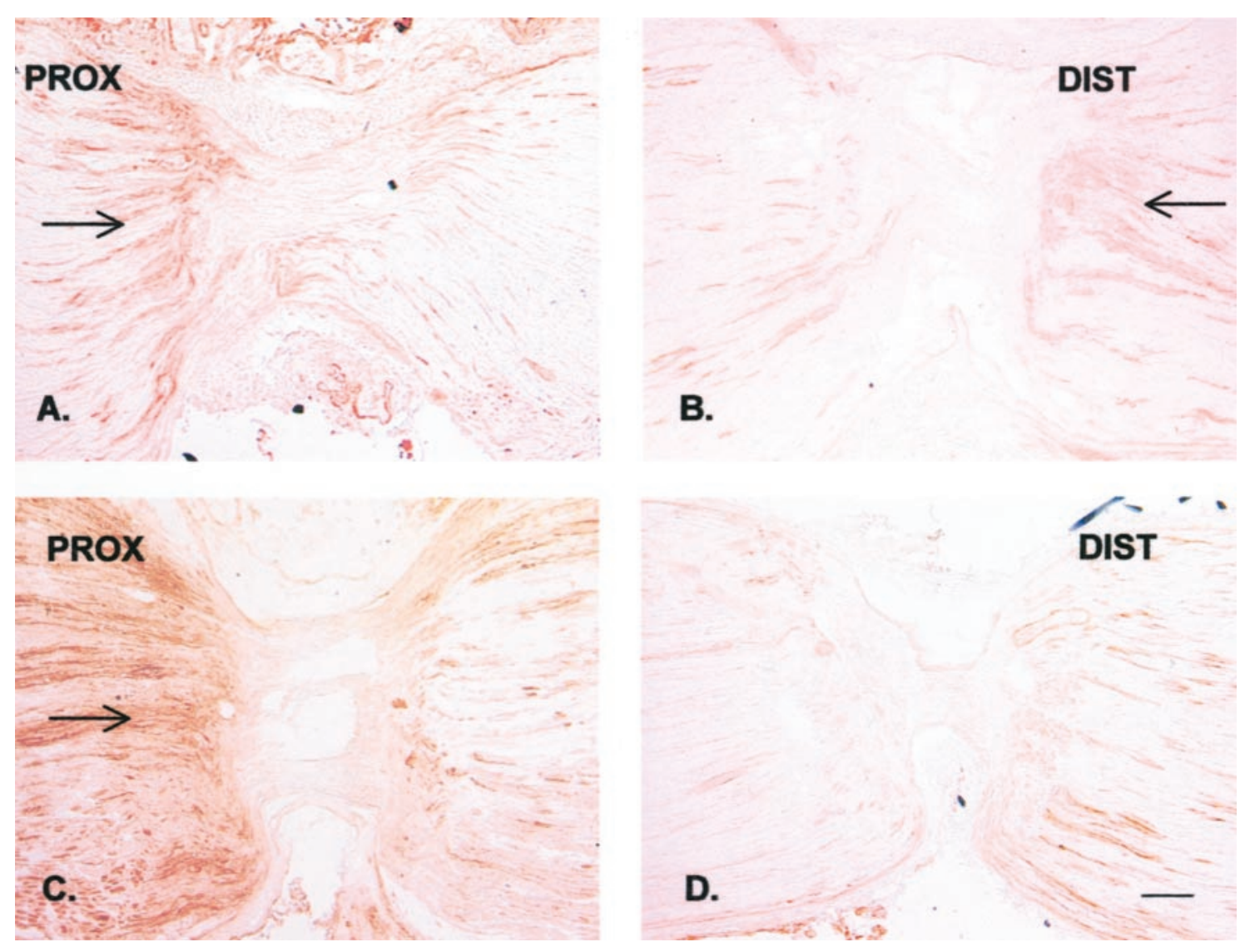

Figure 4. Immunohistochemical staining of endogenous TNF in the rat sciatic nerve proximal (PROX) and distal (DIST) to a DL 20 hr after placement. As in Figures 2 and 3, the proximal (central) side is on the left, and the distal (peripheral) side is on the right. A, B, Endogenous TNF is accumulating proximally and distally to the DL after placement of the ligatures (arrows). $C, D$, After chronic constriction injury, the proximal accumulation of endogenous TNF is markedly increased (arrow), whereas the distal accumulation of TNF remains unchanged. Scale bar, $100 \mu \mathrm{m}$.

injection of ${ }^{125} \mathrm{I}$-TNF, there was no accumulation of ${ }^{125} \mathrm{I}$ in the ipsilateral DRG or spinal cord (Fig. 7B).

\section{Early anterograde transport of exogenous ${ }^{125}$ I-TNF to the innervated muscle}

Potential targets of anterogradely transported TNF are the innervated skin or muscle. To consider these potential targets, ${ }^{125} \mathrm{I}-\mathrm{TNF}$ was injected into the intact sciatic nerve, and radioactivity was measured in plantar skin and gastrocnemius muscle. Six and $20 \mathrm{hr}$ after intraneural injection of ${ }^{125} \mathrm{I}-\mathrm{TNF},{ }^{125} \mathrm{I}$ accumulated in the ipsilateral gastrocnemius muscle, with an early maximum after $6 \mathrm{hr}(p<0.001$ for ipsilateral vs contralateral after 6 hr; Fig. $8 A$ ). To examine the influence of nerve injury on anterograde transport of TNF to the muscle, ${ }^{125}$ I was analyzed $20 \mathrm{hr}$ after intraneural injection of ${ }^{125} \mathrm{I}-\mathrm{TNF} 2 \mathrm{~mm}$ proximally to a CCI or DL made $1 \mathrm{~d}$ earlier (Fig. $8 B$ ). Both types of ligature reduced accumulation of ${ }^{125} \mathrm{I}$ in the ipsilateral muscle significantly $(p<$ 0.05 for ipsilateral muscle with intact nerve vs ipsilateral muscle after DL and ipsilateral muscle after CCI). Unlike the muscle, there was no accumulation of ${ }^{125} \mathrm{I}$ in the ipsilateral skin with an intact or injured sciatic nerve (Fig. 8C).

\section{Potential sources of anterogradely transported TNF}

Potential sources of anterogradely transported TNF are DRG sensory neurons, motor neurons, or Schwann cells within the nerve. Some evidence suggests expression of TNF in motor horn cells (DeLeo et al., 1997; Villarroya et al., 1997). As shown previously, TNF-IR is strongly increased in the sciatic nerve after
CCI (Sommer and Schäfers, 1998). We used double immunofluorescence to localize TNF expression in the peripheral nerve and DRG cells before and after neuronal injury. In the uninjured rat sciatic nerve, TNF-IR could be identified in Schwann cells of myelinated and unmyelinated axons (Fig. 9a). After nerve injury, TNF-IR in activated Schwann cells was greatly increased (Fig. $9 b)$, whereas endoneurial macrophages were not TNFimmunoreactive (data not shown). In the DRG of an intact sciatic nerve, mostly small DRG neurons were TNF-immunoreactive. After CCI, medium-sized to larger DRG neurons that were not isolectin IB4-positive increased their expression of TNF (Fig. $9 c, d)$. This is supported by the quantitative analysis of the crosssectional area of immunoreactive DRG cells before and after CCI. Neurons with a cross-sectional area between 600 and 1000 $\mu \mathrm{m}^{2}$ significantly increased their expression of TNF after CCI $(p<0.05$; Fig. 10). From these results, it is likely that DRG neurons are a major contributing source of anterogradely transported TNF in the intact and injured peripheral nervous system.

\section{DISCUSSION}

Anterograde transport of endogenous and exogenous TNF in the intact and injured peripheral nerve

We have presented several lines of evidence that TNF is anterogradely transported in the rat sciatic nerve. Using the double ligation approach, we demonstrated that endogenous TNF accumulated proximally to a ligation over $20 \mathrm{hr}$. This elevation did not reflect an overall increase in protein in the nerve, because there 
A.

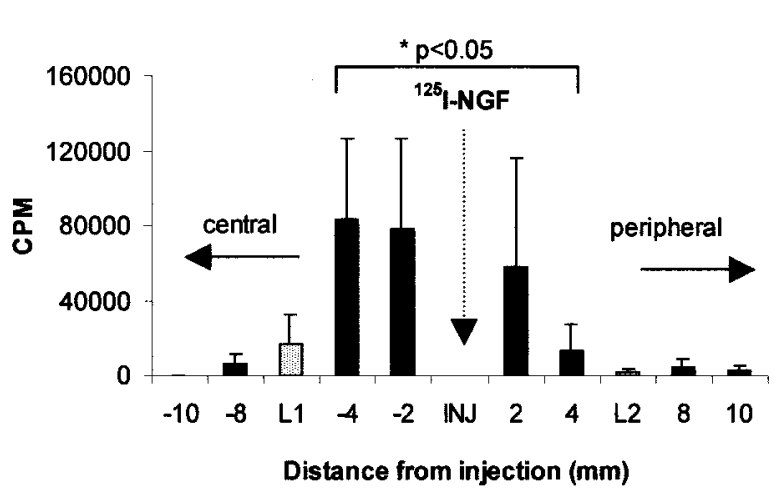

B.

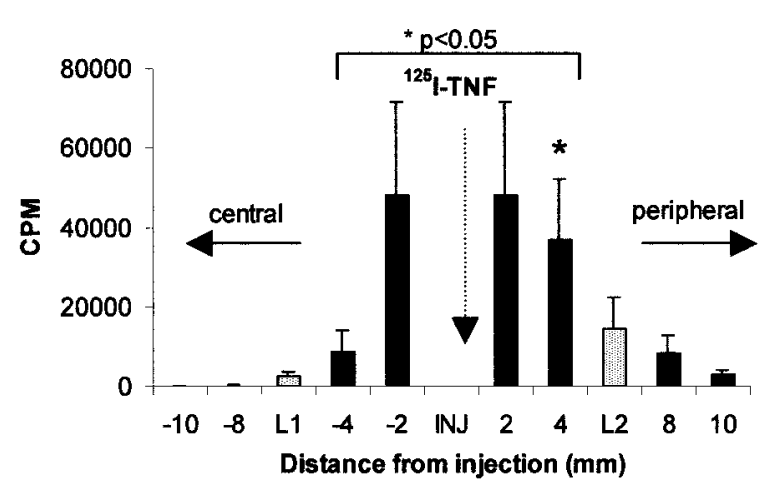

Figure 5. Distribution of ${ }^{125} \mathrm{I}$ in $2 \mathrm{~mm}$ segments of the rat sciatic nerve 20 hr after intraneural injection $(I N J)$ of ${ }^{125} \mathrm{I}-\mathrm{NGF}(A)$ or ${ }^{125} \mathrm{I}-\mathrm{TNF}(B)$ between a double ligature. The double ligature was placed before injection; the proximal (central) ligature $(L 1)$ is on the left, and the distal (peripheral) ligature (L2) is on the right. Data represent mean counts per minute $(C P M) \pm$ SEM for each nerve segment. $A$, After injection of ${ }^{125} \mathrm{I}-\mathrm{NGF},{ }^{125} \mathrm{I}$ accumulates distally to the proximal ligature $(L 1)$ but not proximally to the distal ligature $(L 2)$, suggesting exclusive retrograde transport $\left({ }^{*} p<0.05\right.$ for segment -4 vs segment 4$)$. $B$, After injection of ${ }^{125} \mathrm{I}-\mathrm{TNF},{ }^{125}$ I significantly accumulates proximally to the distal ligature $(L 2 ; * p<0.05$ for segment 4 vs segment -4$)$ but not distally to the proximal ligature $(L 1)$, suggesting exclusive anterograde transport.

was no uniform distribution of TNF-IR in the nerve segment between the two ligations, indicating a lack of significant local TNF synthesis or influx. Exogenous intraneural injection of ${ }^{125} \mathrm{I}-$ TNF into a double-ligated nerve resulted in significant accumulation proximal to the ligature. Injection of ${ }^{125} \mathrm{I}-\mathrm{TNF}$ into the intact nerve showed a significant increase of ${ }^{125} \mathrm{I}$-TNF in the distal but not proximal nerve segments. After intraneural injection of ${ }^{125} \mathrm{I}-\mathrm{TNF}$, there was a time-dependent accumulation in the peripheral targets, which surprisingly was exclusively limited to the ipsilateral innervated muscle but not skin.

TNF anterograde transport of endogenous TNF was increased after nerve injury, concomitantly with increased TNF-IR in DRG neurons. Thus, one explanation for the increased amount of TNF transported to the proximal ligature may be the increased availability of the cytokine. Alternatively, as shown for neurotrophins (Tonra et al., 1998), increased TNF transport may be related to upregulation of its cell surface receptors or a redistribution of preexisting receptors within the injured DRG or nerve fibers. Indeed, constitutive TNF receptor 1 (TNFR1) transcripts can be detected in DRG of untreated rats, and TNFR2 is induced after stimulation (Li et al., 2001). In the peripheral nerve, TNFR1 and 2 have been identified and may be responsible for increased
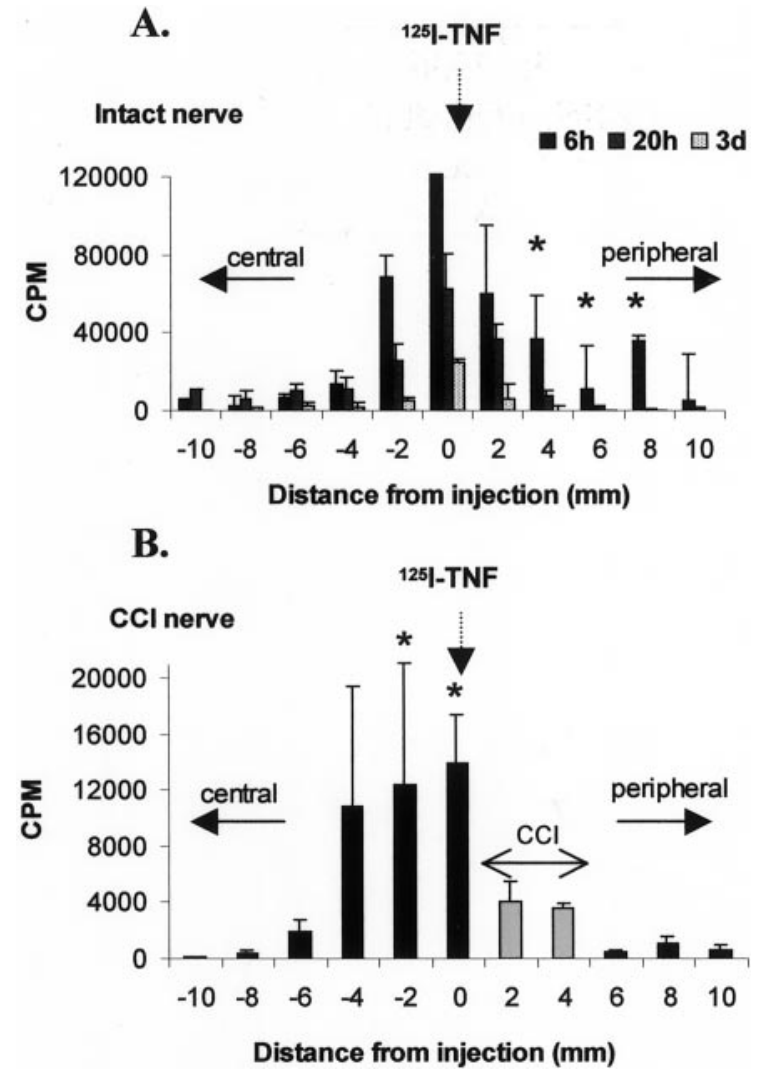

Figure 6. Distribution of ${ }^{125} \mathrm{I}$ in $2 \mathrm{~mm}$ segments of the rat sciatic nerve after intraneural injection of ${ }^{125} \mathrm{I}-\mathrm{TNF}$ in an intact rat sciatic nerve $(A)$ or $2 \mathrm{~mm}$ proximal to a CCI $(B$; gray bars $)$ made $1 \mathrm{~d}$ earlier. The proximal (central) side is on the left, and the distal (peripheral) side is on the right. $A$, In the intact nerve, the nerve segments peripheral to the injection site significantly accumulate ${ }^{125} \mathrm{I}$, suggesting anterograde transport. This accumulation is maximal after $6 \mathrm{hr}\left({ }^{*} p<0.05\right.$ for segments 4,6 , and 8 vs segments $-4,-6$, and -8 ). $B$, After CCI, the intraneurally injected ${ }^{125} \mathrm{I}-\mathrm{TNF}$ is accumulated proximally to the CCI segments $\left({ }^{*} p<0.05\right.$ for segments -2 and 0 vs segments 6 and 8 ).

uptake of TNF (Shubayev and Myers, 2001), possibly from nonneuronal cells, as shown here. Furthermore, neuronal transport may generally be upregulated because of the increase of transport capacity of injured neurons, possibly related to increased expression of axonal transport motor proteins, as shown in axotomized hypoglossal motoneurons (Su et al., 1997).

Anterograde transport of CGRP was also increased after nerve injury in the present study. In a previous study with $\mathrm{CCI}$, the axons spared by the injury increased the axonal transport of CGRP to the ipsilateral gracile nucleus (Ma et al., 1999). However, in other animal models with greater damage to nerve fibers such as crush injury, dorsal rhizotomy, or axotomy, the anterograde transport of CGRP was not increased (Kashiba et al., 1997; Tonra et al., 1998).

\section{No evidence of retrograde transport of TNF to the DRG or spinal cord}

In contrast to a recent study with exogenous biotinylated TNF (Shubayev and Myers, 2001), we found no evidence of retrograde axonal transport of exogenous TNF to the DRG or spinal cord after intraneural, intradermal, or intramuscular injection, although the analysis of the endogenous TNF transport suggested retrograde transport of endogenous TNF in the intact but not in the CCI injured nerve. These results might be related to the 
A.

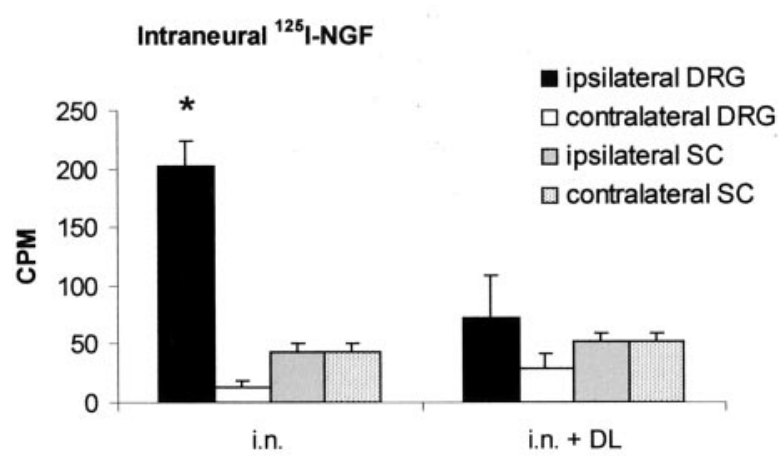

B.

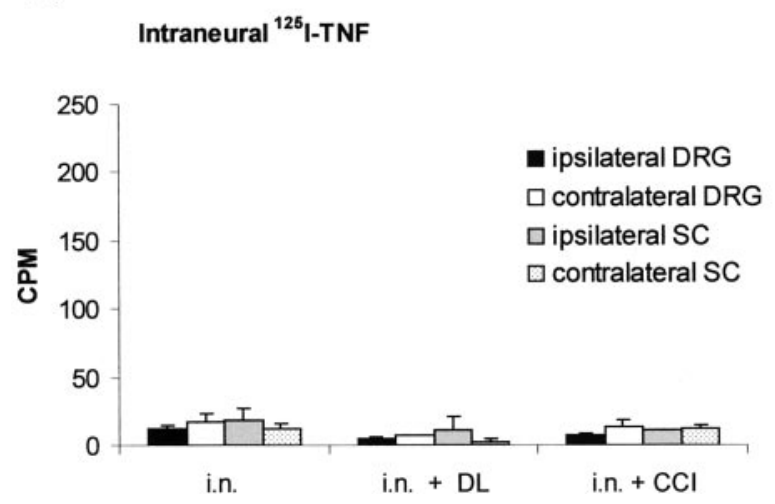

Figure 7. Distribution of ${ }^{125} \mathrm{I}$ in the lumbar DRG and spinal cord $(S C) 20$ $\mathrm{hr}$ after intraneural (i.n.) injection of ${ }^{125} \mathrm{I}-\mathrm{NGF}$ or ${ }^{125} \mathrm{I}-\mathrm{TNF}$ into the rat sciatic nerve. $A$, After injection of ${ }^{125} \mathrm{I}-\mathrm{NGF},{ }^{125} \mathrm{I}$ significantly accumulated in the ipsilateral DRG but not in SC, suggesting retrograde transport to the DRG. This transport could be inhibited by placement of a DL around the injection site $\left({ }^{*} p<0.05\right.$ for ipsilateral DRG after injection into the intact vs double-ligated nerve). $B$, After injection of ${ }^{125} \mathrm{I}$-TNF in the intact, double-ligated, or chronically constricted nerve, there was no accumulation of ${ }^{125} \mathrm{I}$ in the DRG or SC. CPM, Counts per minute.

different techniques. First, biotinylated and radiolabeled TNF may not share the same characteristics regarding transport mechanisms, because biotin itself and its derivates are known to be anterogradely and retrogradely transported (Halfter, 1987; Lapper and Bolam, 1991) and may produce collateral labeling of parallel fibers (Chen and Aston-Jones, 1998). Second, different sites of injection have been shown to change the amount and time course of the transport of the substance injected (Curtis et al., 1998). In our study, radioligands were injected $2 \mathrm{~mm}$ proximally to the nerve lesion, which is reported to produce a long-lasting increase of anterograde transport for neurotrophins (Curtis et al., 1998). Injection directly into the nerve injury site causes a high but short-lasting increase of axonal transport, possibly attributable to local changes in the membrane structure and turnover at the site of injury (Kristensson and Olsson, 1976; Malmgren et al., 1978; Curtis et al., 1998). The injection of ${ }^{125} \mathrm{I}-\mathrm{NGF}$, our positive control for retrograde transport, resulted in a significant accumulation in the ipsilateral but not in the contralateral DRG after intraneural and intradermal injection. In accordance with other studies using nerve crush (Curtis et al., 1998), we found significant retrograde transport of exogenous ${ }^{125} \mathrm{I}-\mathrm{NGF}$ to the DRG after CCI, which was in line with an elevated content of ${ }^{125} \mathrm{I}-\mathrm{NGF}$ in the ipsilateral sciatic nerve segments after intramuscular injection. ${ }^{125}$ I-NGF also accumulated in the ipsilateral DRG after intradermal injection, suggesting retrograde transport in sensory

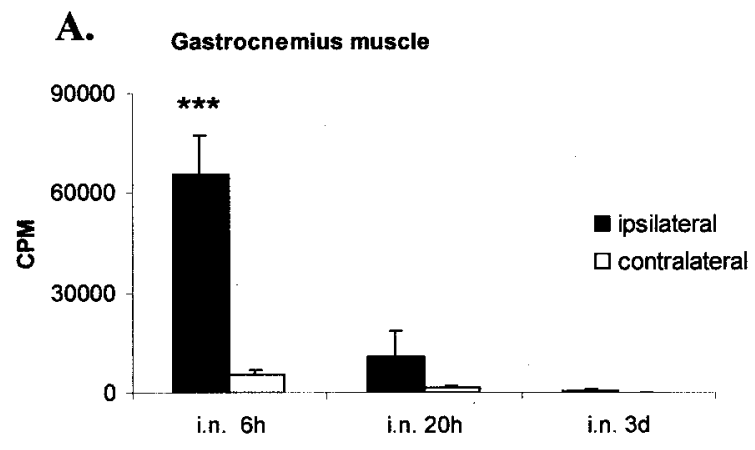

B. Gastrocnemius muscle
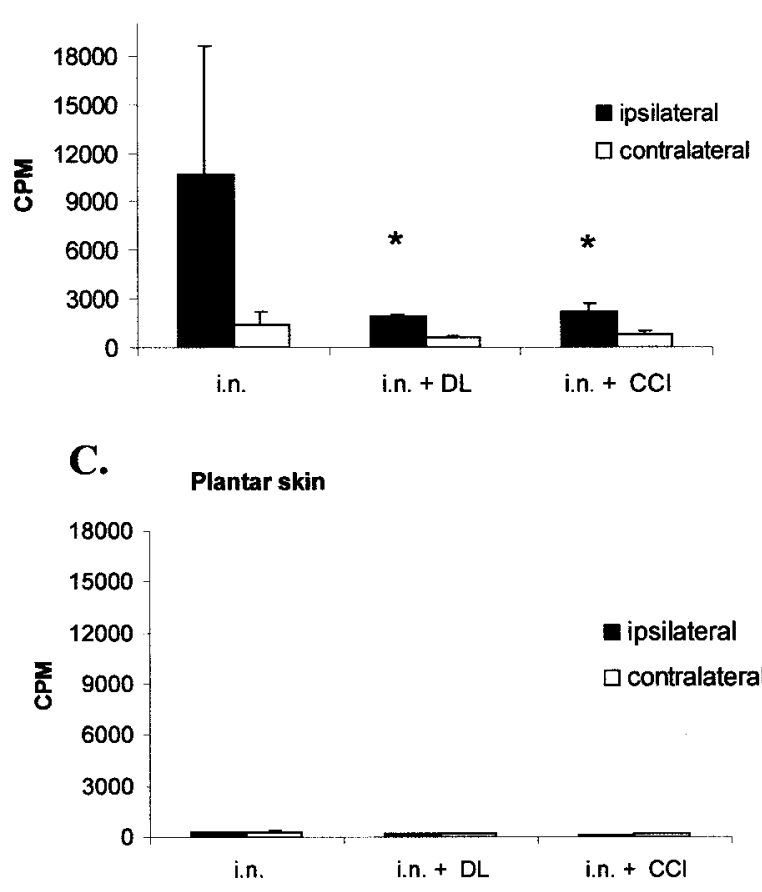

Figure 8. Distribution of ${ }^{125} \mathrm{I}$ in the gastrocnemius muscle or plantar skin after intraneural (i.n.) injection of ${ }^{125}$ I-TNF. $A$, Temporal course of accumulation of ${ }^{125} \mathrm{I}$ in the ipsilateral and contralateral gastrocnemius muscle. After $6 \mathrm{hr}$, the ipsilateral gastrocnemius muscle shows a significant increase of ${ }^{125} \mathrm{I}-\mathrm{TNF}(* * * p<0.001$ for ipsilateral vs contralateral gastrocnemius muscle), suggesting fast anterograde transport. After $20 \mathrm{hr}$ there is still a trend of accumulation in the ipsilateral gastrocnemius muscle, which is not statistically significant. $B$, The accumulation of ${ }^{125} \mathrm{I}$ in the ipsilateral gastrocnemius muscle $20 \mathrm{hr}$ after injection can be blocked by a DL or CCI of the sciatic nerve made before the injection, suggesting axonal transport $\left({ }^{*} p<0.05\right.$ for intraneural injection in the intact nerve vs intraneural injection within a DL or proximally to a $\mathrm{CCI}$ ). $C$, There is no accumulation of ${ }^{125} \mathrm{I}$ in the plantar skin after injection of ${ }^{125} \mathrm{I}-\mathrm{TNF}$ into the intact, double-ligated, or CCI-lesioned sciatic nerve. CPM, Counts per minute.

neurons. NGF is known to promote the survival and regeneration of sensory neurons after nerve injury (Otto et al., 1987; Rich et al., 1987, 1989; Gold et al., 1991). As shown previously, ${ }^{125}$ I-NGF did not accumulate in the spinal cord of unlesioned rats or in rats after nerve injury (DiStefano et al., 1992).

\section{Fibers, targets, and possible sources of TNF anterograde transport}

Axonal transport of TNF resulted in an early accumulation of ${ }^{125} \mathrm{I}$ in the ipsilateral but not contralateral gastrocnemius muscle 6 hr after injection. The exclusive accumulation of ${ }^{125} \mathrm{I}-\mathrm{TNF}$ in the 

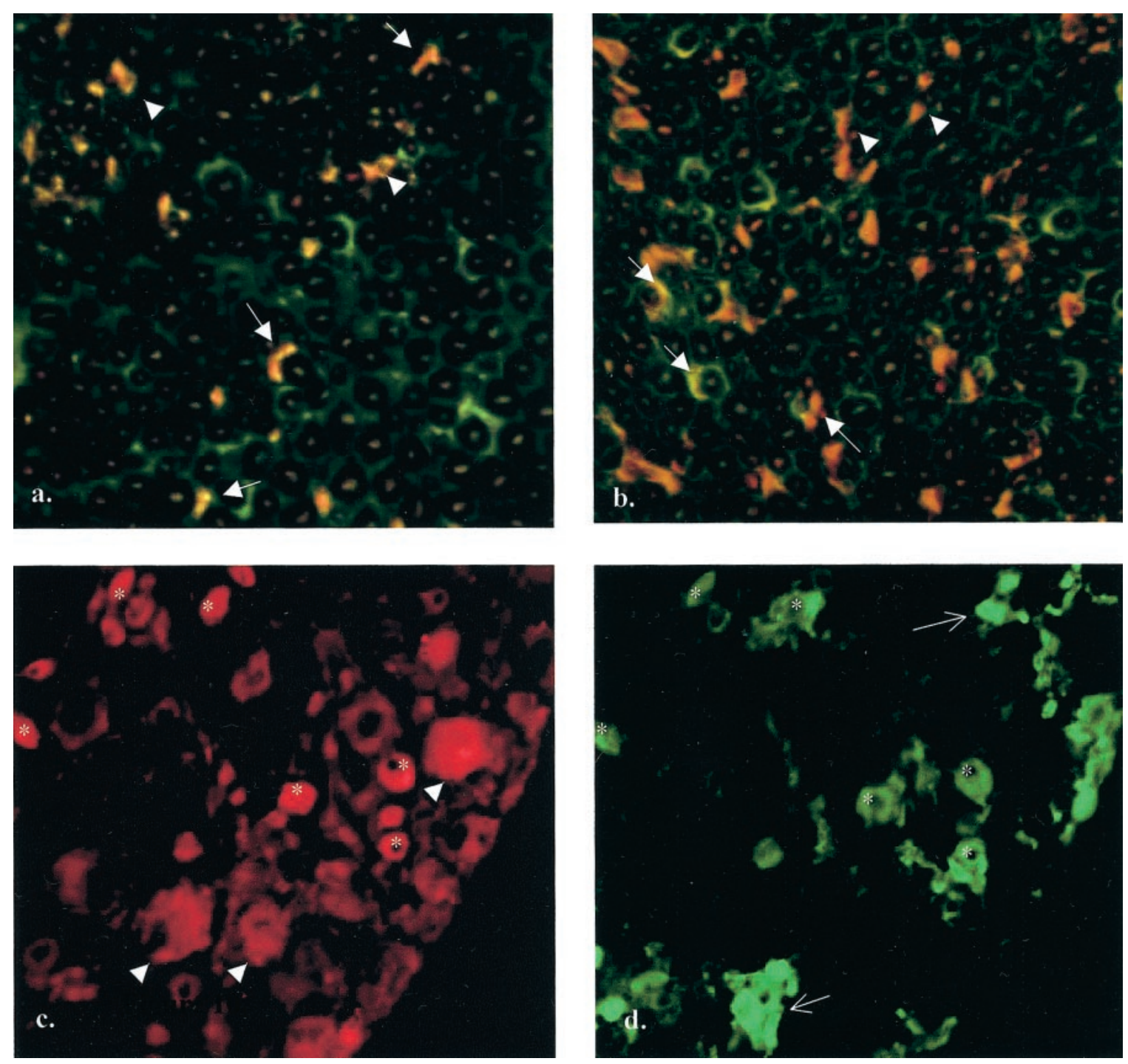

Figure 9. Double immunofluorescence for endogenous TNF in the rat sciatic nerve and lumbar DRG before and after CCI. $A, B$, Twelve micrometer cryosections of rat sciatic nerve immunostained for TNF and S-100 (Schwann cell antigen). TNF-immunoreactive structures appear red; S-100immunoreactive structures appear green; and colocalization of the antigens appears orange. $A$, In the uninjured nerve, TNF-IR is shown in Schwann cells of myelinated (arrows) and unmyelinated (arrowheads) axons. B, In a $12 \mu \mathrm{m}$ sciatic nerve $3 \mathrm{~d}$ after CCI, the number of TNF-IR Schwann cells has greatly increased (arrows, arrowheads). C, D, Ten micrometer cryosection of rat DRG $4 \mathrm{~d}$ after CCI, immunostained for TNF (red) and isolectin IB4 (green) Small DRG neurons are immunoreactive for TNF; some of them are also IB4 positive (asterisks). Other small DRG neurons are IB4-positive but not TNF-positive (arrows). In addition, medium-sized and large DRG neurons express TNF and are not IB4-positive (arrowheads).

ipsilateral muscle but not in skin may suggest specific axonal transport of TNF in possibly medium-sized or even larger fibers. This is congruent with the fast transport rate of TNF, which is in accordance with the fast transport rate of most of the neurotrophins (Vallee and Bloom, 1991). The model of nerve injury chosen in this study, the CCI, causes injury of predominantly large fibers (Sommer et al., 1995; Daemen et al., 1998), which may explain why TNF anterograde transport was disturbed distally to this lesion. A mechanical block of transport by the CCI ligatures may also be considered. The lack of TNF accumulation in the innervated skin might also be related to technical issues. The physical size and level of innervation of skin compared with the gastrocnemius muscle is much smaller; therefore, TNF accumulation in the free nerve endings of skin might be not detectable with the techniques used in the present study. Alternatively, small neurons labeled for TNF in the DRG may subserve noncutane- ous functions. Additional studies with more sensitive detection techniques, such as emulsion autoradiography, might address these questions.

There are several potential sources of anterogradely transported TNF. Within the peripheral nerve, non-neuronal cells, primarily Schwann cells, express TNF (Wagner and Myers, 1996a; Sommer and Schäfers, 1998). Axonal transport of Schwann cell-derived TNF requires cytokine uptake by axonal receptors from these non-neuronal cells into the nerve. These axonal receptors may be the underlying mechanism for the axonal transport of intraneurally injected TNF. In addition, sensory neurons in the DRG are a second potential source of anterogradely transported endogenous TNF. In the intact nervous system, mostly small DRG neurons are TNF-immunoreactive. After CCI, medium-sized to large DRG neurons increase their expression of TNF. 


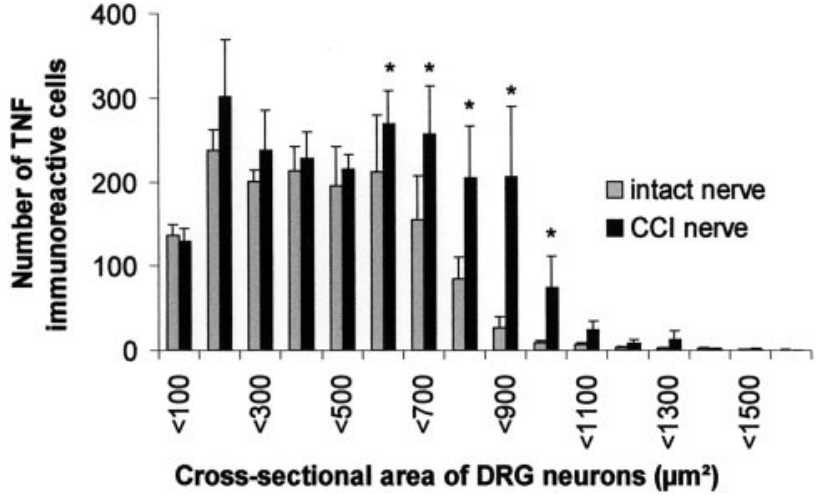

Figure 10. Histogram illustrating the size distribution of TNFimmunoreactive DRG neuronal profiles before (gray bars) and $4 \mathrm{~d}$ after (black bars) CCI. In the intact nervous system, most TNFimmunoreactive DRG cells are small. After CCI, TNF immunoreactivity is increased exclusively in medium-sized to large DRG neurons $\left(^{*} p<\right.$ 0.05 for cells with a cross-sectional area between 600 and $1000 \mu \mathrm{m}^{2}$, compared before and after CCI).

\section{Possible role of anterogradely transported TNF}

There are several hypotheses for the physiological role played by anterogradely transported TNF. Because anterograde transport of endogenous TNF to the peripheral nerve injury site is increased after CCI, it may be relevant to pain-associated behavior after nerve injury. Anterogradely transported TNF accumulates in muscle but not in skin. Interestingly, axotomized and intact muscle afferents but not skin afferents develop ongoing activity of dorsal root origin after a peripheral nerve lesion (Michaelis et al., 2000). Anterogradely transported TNF may also be relevant for early degenerative pathology. For example, TNF may take part in the regulation of degeneration and regeneration by inhibiting the protective effects of another anterogradely transported molecule, IGF-1, because these two factors are thought to have opposing effects (Loddick and Rothwell, 1999; von Bartheld et al., 2001).

In conclusion, TNF is specifically transported to the innervated muscle, and after damage to the peripheral nerve, TNF anterograde transport is dramatically increased. The specificity of these findings suggests an important role for this cytokine in the function of the peripheral nervous system and in the response to nerve injury.

\section{REFERENCES}

Ben-Jonathan N, Maxson RE, Ochs S (1978) Fast axoplasmic transport of noradrenaline and dopamine in mammalian peripheral nerve. J Physiol (Lond) 281:315-324.

Bizette C, Chan-Chi-Song P, Fontaine M, Tadie M (1996) Expression des ARNm de l'interleukine 1 beta, de l'interleukine 6 et du tumor necrosis factor alpha au cours de la regeneration du nerf sciatique de rat apres perte de substance. Chirurgie 121:474-481.

Chen S, Aston-Jones G (1998) Axonal collateral-collateral transport of tract tracers in brain neurons: false anterograde labelling and useful tool. Neuroscience 82:1151-1163.

Colburn RW, DeLeo JA (1999) The effect of perineural colchicine on nerve injury-induced spinal glial activation and neuropathic pain behavior. Brain Res Bull 49:419-427.

Cougnon-Aptel N, Whiteside GT, Munglani R (1999) Effect of colchicine on neuropeptide $\mathrm{Y}$ expression in rat dorsal root ganglia and spinal cord. Neurosci Lett 259:45-48.

Curtis R, Tonra JR, Stark JL, Adryan KM, Park JS, Cliffer KD, Lindsay RM, DiStefano PS (1998) Neuronal injury increases retrograde axonal transport of the neurotrophins to spinal sensory neurons and motor neurons via multiple receptor mechanisms. Mol Cell Neurosci 12:105-118.

Daemen MA, Kurvers HA, Bullens PH, Slaaf DW, Freling G, Kitslaar PJ, van den Wildenberg FA (1998) Motor denervation induces altered muscle fibre type densities and atrophy in a rat model of neuropathic pain. Neurosci Lett 247:204-208.

DeLeo JA, Colburn RW, Rickman AJ (1997) Cytokine and growth factor immunohistochemical spinal profiles in two animal models of mononeuropathy. Brain Res 759:50-57.

DiStefano PS, Friedman B, Radziejewski C, Alexander C, Boland P, Schick CM, Lindsay RM, Wiegand SJ (1992) The neurotrophins BDNF, NT-3, and NGF display distinct patterns of retrograde axonal transport in peripheral and central neurons. Neuron 8:983-993.

Filliatreau G, Attal N, Hassig R, Guilbaud G, Desmeules J, DiGiamberardino L (1994) Time-course of nociceptive disorders induced by chronic loose ligatures of the rat sciatic nerve and changes of the acetylcholinesterase transport along the ligated nerve. Pain 59:405-413.

Gold BG, Mobley WC, Matheson SF (1991) Regulation of axonal caliber, neurofilament content, and nuclear localization in mature sensory neurons by nerve growth factor. J Neurosci 11:943-955.

Griffin JW, George R, Ho T (1993) Macrophage systems in peripheral nerves. A review. J Neuropathol Exp Neurol 52:553-560.

Halfter W (1987) Anterograde tracing of retinal axonas in the avian embryo with low molecular weight derivatives of biotin. Dev Biol 119:322-335.

Ishida-Yamamoto A, Senba E, Tohyama M (1989) Distribution and fine structure of calcitonin gene-related peptide-like immunoreactive nerve fibers in the rat skin. Brain Res 491:93-101.

Jakobsen J, Sidenius P (1983) Early and dose-dependent decrease of retrograde axonal transport in acrylamide-intoxicated rats. J Neurochem 40:447-454.

Johnson EM, Taniuchi M, Clark HB, Springer JE, Koh S, Tayrien MW, Loy R (1987) Demonstration of the retrograde transport of nerve growth factor receptor in the peripheral and central nervous system. J Neurosci 7:923-929.

Kashiba H, Ueda Y, Ueyama T, Nemoto K, Senba E (1997) Relationship between BDNF- and trk-expressing neurones in rat dorsal root ganglion: an analysis by in situ hybridization. NeuroReport 8:1229-1234

Kingery WS, Guo TZ, Poree LR, Maze M (1998) Colchicine treatment of the sciatic nerve reduces neurogenic extravasation, but does not affect nociceptive thresholds or collateral sprouting in neuropathic or normal rats. Pain 74:11-20.

Korsching S, Thoenen H (1985) Nerve growth factor supply for sensory neurons: site of origin and competition with the sympathetic nervous system. Neurosci Lett 54:201-205.

Kristensson K, Olsson Y (1976) Retrograde transport of horseradish peroxidase in transected axons. III. Entry into injured axons and subsequent localization in perikaryon. Brain Res 115:201-213.

Kruger L, Sampogna SL, Rodin BE, Clague J, Brecha N, Yeh Y (1985) Thin-fiber cutaneous innervation and its intraepidermal contribution studied by labeling methods and neurotoxin treatment in rats. Somatosens Res 2:335-356.

La Fleur M, Underwood JL, Rappolee DA, Werb Z (1996) Basement membrane and repair of injury to peripheral nerve: defining a potential role for macrophages, matrix metalloproteinases, and tissue inhibitor of metalloproteinases-1. J Exp Med 184:2311-2326.

Lapper SR, Bolam JP (1991) The anterograde and retrograde transport of neurobiotin in the central nervous system of the rat: comparison with biocytin. J Neurosci Methods 39:163-174.

Li JY, Kling-Petersen A, Dahlstrom A (1992) Influence of spinal cord transection on the presence and axonal transport of CGRP-, chromogranin A-, VIP-, synapsin I-, and synaptophysin-like immunoreactivities in rat motor nerve. J Neurobiol 23:1094-1110.

Li Y, Ji A, Bender F, Bette M, Weihe E, Schafer MK-H (2001) Neuronal and non-neuronal expression of TNF receptors in rat dorsal root ganglion: effects of LPS. Soc Neurosci Abstr 27:52.2.

Loddick SA, Rothwell NJ (1999) Mechanisms of tumor necrosis factor alpha action on neurodegeneration: interaction with insulin-like growth factor-1. Proc Natl Acad Sci USA 96:9449-9451.

Ma W, Ramer MS, Bisby MA (1999) Increased calcitonin gene-related peptide immunoreactivity in gracile nucleus after partial sciatic nerve injury: age-dependent and originating from spared sensory neurons. Exp Neurol 159:459-473.

Malmgren L, Olsson Y, Olsson T, Kristensson K (1978) Uptake and retrograde axonal transport of various exogenous macromolecules in normal and crushed hypoglossal nerves. Brain Res 153:477-493.

Michaelis M, Liu X, Janig W (2000) Axotomized and intact muscle afferents but no skin afferents develop ongoing discharges of dorsal root ganglion origin after peripheral nerve lesion. J Neurosci 20:2742-2748.

Miller MS, Spencer PS (1985) The mechanisms of acrylamide axonopathy. Annu Rev Pharmacol Toxicol 25:643-666.

Murphy PG, Grondin J, Altares M, Richardson PM (1995) Induction of interleukin-6 in axotomized sensory neurons. J Neurosci 15:5130-5138.

Otto D, Unsicker K, Grothe C (1987) Pharmacological effects of nerve growth factor and fibroblast growth factor applied to the transectioned sciatic nerve on neuron death in adult rat dorsal root ganglia. Neurosci Lett 83:156-160. 
Palmatier MA, Hartman BK, Johnson EM (1984) Demonstration of retrogradely transported endogenous nerve growth factor in axons of sympathetic neurons. J Neurosci 4:751-756.

Ranish N, Ochs S (1972) Fast axoplasmic transport of acetylcholinesterase in mammalian nerve fibres. J Neurochem 19:2641-2649.

Rich KM, Luszczynski JR, Osborne PA, Johnson EM (1987) Nerve growth factor protects adult sensory neurons from cell death and atrophy caused by nerve injury. J Neurocytol 16:261-268.

Rich KM, Alexander TD, Pryor JC, Hollowell JP (1989) Nerve growth factor enhances regeneration through silicone chambers. Exp Neurol 105:162-170.

Shubayev VI, Myers RR (2001) Axonal transport of TNF-alpha in painful neuropathy: distribution of ligand tracer and TNF receptors. J Neuroimmunol 114:48-56.

Sommer C, Schäfers M (1998) Painful mononeuropathy in C57BL/Wld mice with delayed Wallerian degeneration: differential effects of cytokine production and nerve regeneration on thermal and mechanical hypersensitivity. Brain Res 784:154-162.

Sommer C, Lalonde A, Heckman HM, Rodriguez M, Myers RR (1995) Quantitative neuropathology of a focal nerve injury causing hyperalgesia. J Neuropathol Exp Neurol 54:635-643.

Sommer C, Marziniak M, Myers RR (1998) The effect of thalidomide treatment on vascular pathology and hyperalgesia caused by chronic constriction injury of rat nerve. Pain 74:83-91.

Sotgiu ML, Biella G, Firmi L, Pasqualucci V (1998) Topical axonal transport blocker vincristine prevents nerve injury-induced spinal neuron sensitization in rats. J Neurotrauma 15:1077-1082.

Su QN, Namikawa K, Toki H, Kiyama H (1997) Differential display reveals transcriptional up-regulation of the motor molecules for both anterograde and retrograde axonal transport during nerve regeneration. Eur J Neurosci 9:1542-1547.
Taskinen HS, Olsson T, Bucht A, Khademi M, Svelander L, Roytta M (2000) Peripheral nerve injury induces endoneurial expression of IFNgamma, IL-10 and TNF-alpha mRNA. J Neuroimmunol 102:17-25.

Tonra JR, Curtis R, Wong V, Cliffer KD, Park JS, Timmes A, Nguyen T, Lindsay RM, Acheson A, DiStefano PS (1998) Axotomy upregulates the anterograde transport and expression of brain-derived neurotrophic factor by sensory neurons. J Neurosci 18:4374-4383.

Vallee RB, Bloom GS (1991) Mechanisms of fast and slow axonal transport. Annu Rev Neurosci 14:59-92.

Villarroya H, Marie Y, Ouallet JC, Le Saux F, Tchelingerian JL, Baumann N (1997) Expression of TNF alpha in central neurons of Lewis rat spinal cord after EAE induction. J Neurosci Res 49:592-599.

von Bartheld CS, Wang XX, Butowt R (2001) Anterograde axonal transport, transcytosis, and recycling of neurotrophic factors: the concept of trophic currencies in neural networks. Mol Neurobiol 24:1-28.

Wagner R, Myers RR (1996a) Schwann cells produce tumor necrosis factor alpha: expression in injured and non-injured nerves. Neuroscience 73:625-629.

Wagner R, Myers RR (1996b) Endoneurial injection of TNF-alpha produces neuropathic pain behaviors. NeuroReport 7:2897-2901.

White DM, Mansfield K, Kelleher K (1996) Increased neurite outgrowth of cultured rat dorsal root ganglion cells following transection or inhibition of axonal transport of the sciatic nerve. Neurosci Lett 208:93-96.

Yamamoto T, Yaksh TL (1993) Effects of colchicine applied to the peripheral nerve on the thermal hyperalgesia evoked with chronic nerve constriction. Pain 55:227-233.

Zhou XF, Rush RA (1996) Endogenous brain-derived neurotrophic factor is anterogradely transported in primary sensory neurons. Neuroscience 74:945-953. 